\title{
Pediatric transport medicine: a yet unknown territory in Korea
}

Jeong-Min Ryu, MD, $\mathrm{PhD}^{1,2}$

${ }^{1}$ Pediatric Emergency Center, Asan Medical Center, Seoul, Korea; ${ }^{2}$ Department of Emergency Medicine, Asan Medical Center, Seoul, Korea

\section{Key message}

Pediatric transport medicine and services are required to reduce the incidence of transport-related morbidity during the interfacility transport of critically ill or injured children.

In the United States, pediatric emergency medicine and critical care physicians, nurses, respiratory therapists, and paramedics specially trained for pediatric transport collaborate in the field of pediatric transport medicine (PTM), a field that is not yet established in Korea. ${ }^{1-6)}$

The basic components of PTM services include a regional network of community hospitals and pediatric emergency centers, a hotline for established communication and dispatch that facilitates transfer to the pediatric center, emergency transport vehicles, experienced pediatric medical control physicians (MCPs), a pediatric critical care or pediatric emergency medicine (or neonatology) team leader, a multidisciplinary team of specially trained pediatric transport professionals, established operational and clinical policies, and a database for quality and performance assessment.

Because most physicians in community hospitals occasionally encounter critically ill or injured children, they should know whom to contact for help (as well as when and how) with patient management and transfer. They should know the hotline number for the communication and dispatch center (e.g., 1800-3323 of the National Medical Center in Korea). A nurse or paramedic on this phone line communicates with emergency departments in regional hospitals to determine the availability of beds in pediatric intensive care units (PICUs). Unfortunately, there are insufficient PICU beds in Korea. We can use the Seoul Mobile Intensive Care Unit (+82-2-762-2525, $+82-2-870-1990$ ) upon determining the receiving hospital in Seoul. Although the MCP position is not fully established yet in Korea, the holder of this position provides pediatric transport, and requires pediatric emergency medicine and critical care expertise. The MCP should be available on phone or radio and not accompany the team. The MCP can either recommend directly or ask other subspecialists for further urgent testing or therapeutic interventions of the referring physician before the transport team arrives. The MCP determines the best team composition and vehicle for transport, including the need for physician accompaniment. The transport team leader should notify the MCP before transporting the child to the receiving facility.

There is evidence of a lower incidence of transport-related morbidity of critically ill or injured children transported by pediatric specialty teams than for those transported by generalist teams. In 2001-2002 in the United States, the presence of a specialized pediatric transport team was associated with decreas. ed mortality (23\% vs. 9\%) and adverse events during transport (61\% vs. 1.5\%). ${ }^{7)}$ Between 2005 and 2008 in the United King. dom, the presence of a specialized pediatric transport team was associated with a decrease in mortality in 29 PICUs in England and Wales (adjusted odds ratio, 0.58; 95\% confidence interval, $0.39-0.87) .{ }^{8)}$

In the current issue of Clinical and Experimental Pediatrics, Chaichotjinda et al. ${ }^{9)}$ reported a 22\% incidence of adverse events during the transport of critically ill children in a Thailand hospital. The noncomplication group showed a more frequent presence of physicians during transport $(76 \%$ vs. $92 \%, P=$ 0.028). Theoretically, the MCP should be responsible for assembling and monitoring the escort team members during transport. Although the study was limited by its single-center design, retrospective nature, small number of cases, and absence of multivariate analysis findings, the study suggests that we should hasten the establishment of PTM services in Korea.

See the article "Assessment of interhospital transport care for pediatric patients" via https://doi.org/10.3345/kjp.2019.00024.

\section{References}

1. American Academy of Pediatrics Committee on Hospital Care: Guidelines for Air and Ground Transportation of Pediatric Patients. Pediatrics 1986;78:943-50.

2. Venkataraman ST, Rubenstein JS, Orr RA. Interhospital transport. A pediatric perspective. Crit Care Clin 1992;8:515-23.

Corresponding author: Jeong-Min Ryu, MD. Pediatric Emergency Center, Asan Medical Center, 88, Olympic-ro 43-GIL, Songpa-gu, Seoul 05505, Korea 凶E-mail: qweynaver@naver.com, https://orcid.org/0000-0002-6854-3090

Received: 8 October, 2019, Revised: 2 May, 2020, Accepted: 6 May, 2020

This is an open-access article distributed under the terms of the Creative Commons Attribution Non-Commercial License (http://creativecommons.org/licenses/bync/4.0/) which permits unrestricted non-commercial use, distribution, and reproduction in any medium, provided the original work is properly cited.

Copyright @ 2020 by The Korean Pediatric Society 
3. Joyce CN, Libertin R, Bigham MT. Family-centered care in pediatric critical care transport. Air Med J 2015;34:32-6.

4. Kissoon N. Pediatric critical care transport: diagnostic uncertainty--no worries, resource limitation--worry. Pediatr Crit Care Med 2008;9:1167.

5. Wheeler DS, Sperring JL, Vaux KK, Poss WB. Development of a pediatric critical care transport team: experience at a military medical center. Mil Med 1999;164:188-93.

6. Pon S, Notterman DA. The organization of a pediatric critical care transport program. Pediatr Clin North Am 1993;40:241-61.
7. Orr RA, Felmet KA, Han Y, McCloskey KA, Dragotta MA, Bills DM, et al. Pediatric specialized transport teams are associated with improved outcomes. Pediatrics 2009;124:40-8.

8. Ramnarayan P, Thiru K, Parslow RC, Harrison DA, Draper ES, Rowan KM. Effect of specialist retrieval teams on outcomes in children admitted to paediatric intensive care units in England and Wales: a retrospective cohort study. Lancet 2010;376:698-704.

9. Chaichotjinda K, Chantra M, Pandee U. Assessment of interhospital transport care for pediatric patients. Clin Exp Pediatr 2019 Aug 29 [Epub]. https://doi.org/10.3345/kjp.2019.00024. 